\title{
In a world of globalization - company valuations of industrial corporates and digital natives
}

\author{
Raphaela Balzer ${ }^{1, *}$ \\ ${ }^{1}$ Technical University of Kosice, Faculty of Economics, Letna 9, 04001 Kosice, Slovak Republic
}

\begin{abstract}
When Brian Arthur referred to a "split" globalized business world in 1996, he distinguishes between industrialized companies from the "Marshall" world and networked technology companies in a world of complexity. By transferring this fundamental split to the era of digitalization superseding the era of industrialization, the question whether digital native companies outperform industrial corporates remains unanswered. Therefore, by using the financial concept of PVGO for company valuations and cluster analysis, the present paper tests the H0 hypothesis of the non-existence of digital native companies which drive market valuations beyond 1 trillion USD. One of the first key results of this paper reveals a clear tendency of digital native companies to dominate market valuations of equity, based on extra-ordinary high PVGO growth rates. Meanwhile, industrial companies exhibit a clear trend towards high PVEA rates which originate from stable cash flows of existing assets. This leads to the rejection of the $\mathrm{H} 0$ hypothesis and to the following conclusion: As the economic dominance of the digital players is reflected in concentrated market valuations, digital native companies outperform their industrial peers according to the notion that "the winner takes it all".
\end{abstract}

\section{Introduction}

The paradigm of digital dominance has not gained fame over night: already in 1996, Arthur [1] has drawn a picture of a bifurcated global business world: on the one hand, industrial corporations are run on the principle of optimization with diminishing returns. On the other hand, tech companies dominate in a world of increasing returns which is mainly characterized by adoption. And today? Has the former quasi-monopolistic power of Microsoft in the mid-nineties been superseded by the Silicon Valley born unicorns like Alphabet and Amazon?

From the investor's perspective, there is a sneaking suspicion if and how market values of the digital native companies can skyrocket beyond 1 trillion USD. Managers and academics alike try to make sense of the "puzzle" of value creation in the era of digital dominance.

Schwartz and Moon [2] have contributed significantly to the debate with their rationale model to explain the valuation of Amazon. They refer to the option value of the internet

*Corresponding author: raphaela.balzer@ student.tuke.sk 
firm based on the variance of distribution of future growth rates. In short, high growth and high volatility yield to high value. Therefore, it is worthwhile to consider the real options concept at first and highlight selected empiric studies on value and growth companies at second.

Myers [3] splits the company value of equity into the element of PVEA, real assets generating cash flow streams at a no-growth premise and the present value of growth opportunities, referred to as PVGO. The conceptual split marks the starting point for the real options theory in the field of corporate finance into corporate strategy [4].

While Dixit et al. [5] set a cornerstone with the scientific, yet comprehensive overview of the real options modelling in 1994, they predict the relevance of uncertainty as a key factor in the process of pursuing growth options in form of investment decisions.

The temptation to evaluate the future success of companies with attractive growth prospects has developed in different ways: On the one hand, scientists like Fama and French [6] provide empiric evidence about growth companies outperforming their value peers with higher returns on equity. Nevertheless, the exercise of their growth options results in a decline of profitability in the long run [7].

In the area of behavioural finance, Lakonishok [8] explains the outperformance of an investment portfolio of value stocks compared to growth stocks due to the behaviour of investors who overestimate the growth rates of "glamour" stocks and therefore overpay compared to a value investment strategy. In 2017, Chen [9] claims in his empiric study that growth stocks do not show a significantly higher level of future cash-flow growth rates than value stocks.

On the other hand, the forecast of earnings of growth companies appears to be a "puzzle" as they seem unpredictable [10]. As the results of Gerakos' [11] study in 2018 show, the key performance indicator of book-to-market value, which traditionally distinguishes value from growth companies, is disconnected to the respective value premium. The latest study in 2018 of Campbell et al. [12] argue that long-term investors are better off investing the overall market portfolio rather than value or growth portfolios.

Other academics see advantages for dynamic, digital players. For example, in 2017, Leiblein et al. [13] postulate an accelerated learning curve leading to better resource allocation decisions and thereby increasing the option of a company value. Today, those characteristics are attributed rather to digital native and tech companies than industrial corporates. In addition, Kraft et al. [14] centre their study around the positive relationship of firm value and its corresponding volatility, which is especially valid for companies with high R\&D expenditure.

While the scientific real options approach is a black box to most practitioners, the field of academic research considers investment decisions as an art rather than science [4]. Yet in the digital age of 2017, Trigeorgis and Reuer [15] emphasize the requirement for further academic investigation to integrate the real option principle into managerial practice in future.

It is the objective to shed light on the performance of value and growth companies, represented as industrial corporates and digital natives, in form of a cluster analysis. The concept of real options with the focus on growth options is applied to the S\&P500 in the last decade, aiming to figure out whether a new paradigm of digital value creation is observed.

Scientifically, the acceptance or rejection of the H0 hypothesis of a non-existence of digital native companies which drive market valuations is envisioned. The methodical approach is organized as follows: In section 2, the formulas and variables of the PVGO concept are explained. Next, the data and selection of the companies is elaborated upon. Thereafter, the form of the cluster analysis is described to detect possible patterns with regards to digital and industrial companies. In the adjacent section 3 , the empiric 
results are discussed in a quantitative, qualitative and graphical manner, structured to the core elements of the hierarchical cluster analysis. Finally, the conclusion in section 4 summarizes the interpretation of the analysis and offers an outlook for further research in various perspectives.

\section{Methodology}

\subsection{Selected key performance indicators and formulas}

Linked to the basic formula, as introduced by Brealey et al. [16], the value per share (SPRICE) of a company consists of the two components: the present value of existing assets (PVEA) and present value of growth opportunities (PVGO) (1). Meanwhile, the concept can be transferred on a company level for market value of equity (MVE) (2).

$$
\begin{gathered}
\text { SPRICE }=\text { PVEA }+ \text { PVGO } \\
M V E=P V E A \_T O T A L+P V G O \_T O T A L
\end{gathered}
$$

Furthermore, Brealey et al. [16] refer to both components in relative terms:

$$
\begin{aligned}
& \text { PVEA_REL }=\text { PVEA } / \text { SPRICE }=\text { PVEA_TOTAL } / M V E \\
& P V G O \_R E L=P V G O / S P R I C E=P V G O \_T O T A L / M V E
\end{aligned}
$$

The values of all S\&P500 companies have been sourced from the Thomson Reuters Data Stream data base of July 20th, 2017. As depicted in Table 1, the following variables are selected for the empiric study:

Table 1. Overview of variables

\begin{tabular}{|c|c|c|}
\hline MVE & Market value of equity & In million ('000 000) USD \\
\hline SPRICE & Value per share & In USD \\
\hline PVEA & Present value of existing assets, per share & In USD \\
\hline PVGO & Present value of growth opportunities, per share & In USD \\
\hline PVEA_REL & Present value of existing assets, relative & In \% \\
\hline PVGO_REL & Present value of growth opportunities, relative & In \% \\
\hline PVEA_TOTAL & Present value of existing assets, total equity & In million ('000 000) USD \\
\hline PVGO_TOTAL & Present value of growth opportunities, total equity & In million ('000 000) USD \\
\hline
\end{tabular}

\subsection{Selected companies of S\&P500}

If Brian Arthur`s [1] description regarding a world of complexity economics applies to today's age of digitalization, the digital native companies with their business models on standardization and scaling dominate market value of equity. This can be adequately measured and reflected with the leading stock index S\&P500 of the United States, the most relevant for the capital markets in the home of the Silicon Valley.

Consequently, the aim is set to identify the most valuable companies within a long-term time horizon and focus the analysis on the creation of sustained value, measured in MVE, rather than one-time and short-term effects such as M\&A activities.

Hence, the companies which are subject to the empiric analysis are carefully selected. Due to the claim of an ease of comprehension, the number of companies in the cluster analysis has been restricted to the top 10 companies with the highest market value of equity 
of the S\&P500 of each year, taken on a July 20th, and a minimum of 3 years in the time interval of July 20th, 2002 and July 20th, 2017.

Thereby, the portfolio of companies has minor adaptations over time: Due to its IPO, Facebook is only subject to analysis in 2017. Amazon is selected though it has only been part of the top 10 companies with the highest MVE since 2016. In 2007, 2012, Alphabet A series shares are represented in all years, in 2017, the C series shares are added after their issuance in 2014. For Berkshire Hathaway, the B series shares are selected, because they are more accessible to investors based on a lower level of share price. Those adaptations lead to a selection of the following 21 companies of S\&P500 with the highest values of equity (MVE), here in alphabetical order: AIG, Alphabet A and C series, Amazon, Apple, AT\&T, Bank of America, Berkshire Hathaway, Chevron, Citigroup, Exxon Mobil, Facebook, General Electric, IBM, Intel, Johnson \& Johnson, JP Morgan Chase, Microsoft, Pfizer, Procter \& Gamble and Walmart.

\subsection{Hierarchical cluster analysis}

It is the objective to recognize patterns of company clusters as a part of the unsupervised machine learning procedure. The calculations are processed in Excel and R. The method to identify the optimal number of clusters is the hierarchical cluster analysis with an agglomerative, bottom-up approach. In combination with the chosen parameter of the Euclidean distance and linkage types complete and average, it is the ambition to verify the number of clusters based on multiple parameters.

Moreover, the cluster membership of both linkage types complete and average is validated, and the respective cluster means on a normalized base are interpreted.

As the number of clusters plays a vital role in the hierarchical cluster analysis, the robustness of the selected number of clusters is validated with the approach of k-means clustering. Hereby, the number of clusters is predefined, and the graphical reflection of the elbow scree analysis supports the decision of the optimal number of clusters.

As a summary, the resulting scatter plot of the k-means clustering with the variables PVEA_TOTAL and PVGO_TOTAL is depicted.

\section{Results and Discussion}

\subsection{Euclidean distance matrix}

The normalized distances of the observations in the Euclidean distance matrix allow to derive statements about the similarity and differences of the company performances. The higher the value of Euclidean distance, the less similar are both observations. Logically, low distance values indicate a higher level of similarities between both companies. In 2017, the highest values between the variables of the companies Alphabet A and Procter \& Gamble mean the most significant difference of the respective key performance indicators. AT\&T and Walmart, by contrast, show a high level of similarity with a distance value of only 0,76 .

\subsection{Analysis of the dendrogram}

The result of hierarchical clustering based on the algorithm of average linkage can be inferred from the dendrogram (Fig. 1). 


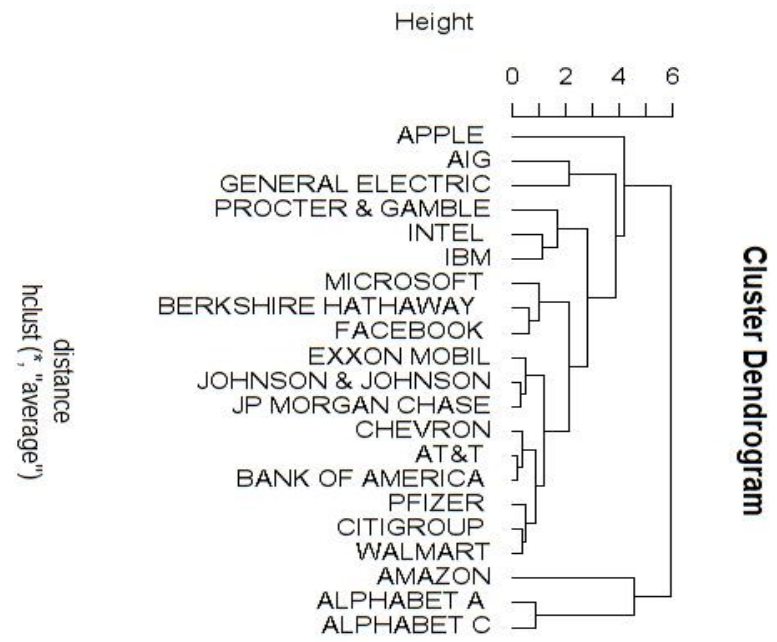

Fig. 1. Dendrogram of selected companies, average linkage type.

As the resulting values of the complete linkage method are widely dispersed, the algorithm shows a high sensitivity to outliers by considering the maximum of values. Therefore, the complete linkage method is not optimally suited for the cluster analysis.

Consequently, the average linkage method illustrates the different nature of digital companies in a more suitable way. The height scale illustrates the respective Euclidean distances. The smaller the value on the height scale, the higher the similarity of the clustered companies: Chevron, AT\&T and Bank of America are grouped on similar values, as well as Exxon Mobil, Johnson \& Johnson and JP Morgan Chase. Meanwhile, as the dendrogram indicates, Alphabet $\mathrm{A}$ and $\mathrm{C}$ and Amazon have a higher level of dissimilarity compared to the classic industrials. Additionally, an industry specific clustering according to banking, pharma or oil cannot be observed.

The results of the supplementary scree plot analysis to reduce the cluster variability when selecting the optimal number of clusters confirm the selected amount of three clusters, balancing an adequate level of distinction with a limited level of complexity.

\subsection{Validation of cluster membership}

Based on the set of 21 companies, a set of three clusters applies. Table 2 allows interpretation in order to compare both linkage types complete and average in terms of their commonalities and clustering:

Table 2. Cluster membership.

\begin{tabular}{|c|c|c|c|}
\multicolumn{1}{c}{ Average linkage } \\
\cline { 2 - 4 } \multicolumn{1}{c|}{ Complete linkage } & Cluster 1 & Cluster 2 & Cluster 3 \\
\hline Cluster 1 & 2 & 0 & 0 \\
\hline Cluster 2 & 0 & 1 & 2 \\
\hline Cluster 3 & 0 & 0 & 16 \\
\hline
\end{tabular}

First, the table shows that two companies have been allocated to cluster 1 with both linkage types. One company has been allocated to a separate cluster 2 and 16 companies have been allocated the cluster 3. The linkage types differ as two companies have been assigned to cluster 2 in the complete linkage type, while being also assigned to cluster 3 
in the average linkage type. The clustering results of both linkage types are robust as 19 of the 21 companies are clustered in an identical way.

\subsection{Robustness test with k-means}

In order to validate the number of three clusters, the method of k-means clustering is applied to the normalized data. The normalized cluster means listed in Table 3 show that the variable PVEA_TOTAL is less relevant for the clustering procedure, while SPRICE and PVGO are essential for cluster 3. Those values can be interpreted that actual profitability is less relevant in the digital age versus the future perspective of growth opportunities.

Table 3. Normalized cluster means of k-means clustering.

\begin{tabular}{|c|c|c|c|c|}
\hline & MVE & SPRICE & PVEA & PVGO \\
\hline Cluster 1 & $-0,060$ & $-0,365$ & $-0,342$ & $-0,346$ \\
\hline Cluster 2 & $-0,809$ & $-0,409$ & $-0,172$ & $-0,562$ \\
\hline Cluster 3 & 1,358 & 2,246 & 1,824 & 2,364 \\
\hline & PVEA_REL & PVGO_REL & PVEA_TOTAL & PVGO_TOTAL \\
\hline Cluster 1 & $-0,215$ & 0,215 & $-0,035$ & $-0,390$ \\
\hline Cluster 2 & 1,455 & $-1,455$ & 0,203 & $-1,159$ \\
\hline Cluster 3 & $-0,934$ & 0,934 & $-0,105$ & 1,727 \\
\hline
\end{tabular}

The measure of realized profit, reflected as PVEA and PVEA_TOTAL, does not impact the share price, which is reflected in the variable SPRICE. In the times of digitalization, the backward direction of historic accounting data plays a minor role for the shareholders. As seen in the empiric cluster analysis, value creation as reflected in market value of equity, is driven by PVGO, the present value of growth opportunities. The value PVGO quantifies the capital market expectations of accelerated growth. Those prospects can be rather substantiated by the increasing returns of digital natives with scaling and business models of standardization, than the "Marshall" world of classic industrials. The graph of Fig. 2 of the K-means clustering emphasizes the impression of a majority in the middle of cluster 1 , a few "losing" companies in the cluster 2 and a concentration of value by the "winners", Alphabet and Amazon, grouped in cluster 3. 


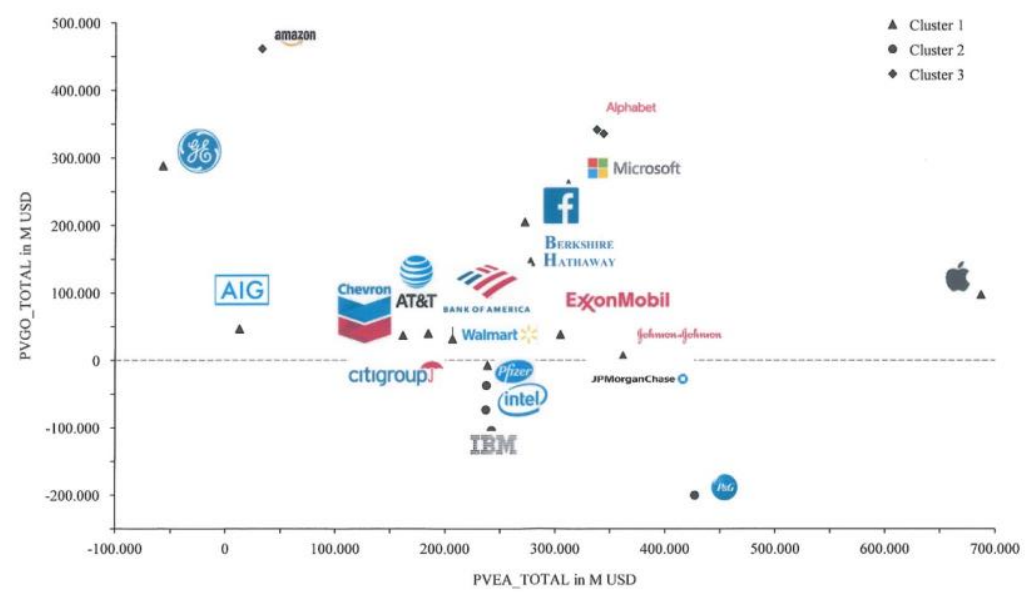

Fig. 2. K-means clustering of selected companies of PVEA_TOTAL and PVGO_TOTAL.

As the results of the hierarchical cluster analysis reveal, the differentiation of valuation between digital native companies and classic industrial companies has been interpreted in a quantitative, qualitative and graphical manner.

\section{Conclusion}

Based on the empiric cluster analysis of the selected companies in 2017, the H0 hypothesis can be rejected. However, it takes a wider approach of research to accept the H1 alternative hypothesis, for this reason, further study and analysis is advisable. In addition, an update on the latest developments of company valuations surpassing the 1 trillion USD hurdle suggest further analysis with even more recent data.

From the investors' perspective, a set of new question arises: could the difference in valuation between digital natives and classic industrials have been identified five or even ten years ago? Which conclusions can be drawn for future investments?

In the senior manager's point of view, the power of value creation has shifted from the optimization of manufacturing to the orchestration of platforms to nurture network effects and scaling. Besides, the dynamics from a pure, historic attitude concentrating on actual profitability have evolved into a future oriented mind set of option-based valuations from the field of corporate finance, accounting for volatility, uncertainty, complexity and ambiguity in a global business context.

From the macro-economic perspective, the field of behavioural economics in a globalized world of complexity economics requires further attention: if customers and investors rather follow other influencers' decisions, the tendency of abnormal profits with a few dominating global monopolists comes without surprise.

Finally, the pressure to obtain attractive return on investment rates in developed markets with partially even negative interest rates leads to the acceptance of higher risks. "New kids on the block" like Alphabet and Amazon benefit from a sheer unlimited access 
to capital. Certainly, the dynamics between digital natives and industrial classics must be carefully observed in future, especially in anticipated downturn market dynamics.

\section{References}

1. W. B. Arthur, Increasing returns and the new world of business. Harvard Business Review, 74(4), 100 (1996)

2. E. S. Schwartz, M. Moon, Rational pricing of internet companies. Financial Analysts Journal, 56(3), 62-75 (2000)

3. S. C. Myers, Determinants of corporate borrowing. Journal of Financial Economics, 5(2), 147-175 (1977)

4. B. M. Lambrecht, Real options in finance. Journal of Banking \& Finance, 81, 166-171 (2017)

5. A. K. Dixit, R. K. Dixit, R. S. Pindyck, Investment under uncertainty. (Princeton university press, Princeton, 1994)

6. E. F. Fama, K. R. French, Size and book-to-market factors in earnings and returns. The Journal of Finance, 50(1), 131-155 (1995)

7. E. F. Fama, K. R. French, The anatomy of value and growth stock returns. Financial Analysts Journal, 63(6), 44-54 (2007)

8. J. Lakonishok, A. Shleifer, R. W. Vishny, Contrarian investment, extrapolation, and risk. The Journal of Finance, 49(5), 1541-1578. (1994)

9. H. Chen, Do cash flows of growth stocks really grow faster?. Journal of Finance, 72(5), 2279-2330. (2017)

10. J. Danbolt, I. R. Hirst, E. Jones, The growth companies puzzle: can growth opportunities measures predict firm growth?, European Journal of Finance, 17(1), 125. (2011)

11. J. Gerakos, J. T. Linnainmaa, Decomposing value. Review of Financial Studies, 31(5), 1825-1854 (2018)

12. J. Y. Campbell, S. Giglio, C. Polk, R. Turley, R. An intertemporal CAPM with stochastic volatility. Journal of Financial Economics, 128(2), 207-233. (2018)

13. M. J. Leiblein, J. S. Chen, H. E. Posen, Resource allocation in strategic factor markets: A realistic real options approach to generating competitive advantage. Journal of Management, 43(8), 2588-2608 (2017)

14. H. Kraft, E. Schwartz, F. Weiss, Growth options and firm valuation. European Financial Management, 24(2), 209-238 (2018)

15. L. Trigeorgis, J. J. Reuer, Real options theory in strategic management. Strategic Management Journal, 38(1), 42-63. (2017)

16. R. A. Brealey, S.C. Myers, F. Allen, P. Mohanty, Principles of Corporate Finance, (McGraw-Hill Education, New York, 2012) 